\title{
Identification of the BCC-Phases in the Structure of Fe-Cr-Ni Alloys Subjected to Arc-Melting and Melt-Spinning
}

\author{
B. KuCHARSKA* AND J. KOWALCZYK
}

Faculty of Production Engineering and Materials Technology, Czestochowa University of Technology, Częstochowa, Poland

(Received April 30, 2019; revised version November 18, 2019; in final form January 10, 2020)

The paper presents tests on three Fe-Cr-Ni alloys belonging to the group of austenitic chromium-nickel steels (AISI 304L, 316L, and 310S). They were remelted in an arc in the atmosphere of argon, and cast on a rotating at $4000 \mathrm{rpm}$ copper drum cooled with water. Using the XRD method, the authors demonstrated the influence of cooling rate and mutual relation of concentrations of $\mathrm{Cr}$ and $\mathrm{Ni}$ alloy additives on the martensitic type of phase formed in steels. It was shown that ferrite $\delta$ is formed in arc-melted 304L and 316L steels. In the 310S steel, which contains more $\mathrm{Cr}$ and $\mathrm{Ni}$ but exhibits a lower $\mathrm{Cr} / \mathrm{Ni}=1.3$ ratio than in the $304 \mathrm{~L}$ and $316 \mathrm{~L}$ steels, after melting in the arc, martensite $\varepsilon$ is formed. As a result of melt-spinning, martensite $\varepsilon$ is formed in all three steels. However, the greatest amount of martensite occurs in the $310 \mathrm{~S}$ steel, while in the $316 \mathrm{~L}$ steel with the highest $\mathrm{Cr} / \mathrm{Ni}$ ratio $(2.2)$, it is the smallest.

DOI: 10.12693/APhysPolA.137.300

PACS/topics: arc-melting, melt-spinning, $\mathrm{Fe}-\mathrm{Cr}-\mathrm{Ni}$ alloys, stainless steels

\section{Introduction}

Among the $\mathrm{Fe}-\mathrm{Cr}-\mathrm{Ni}$ alloys, austenitic steels from the AISI300 series are of great construction and application importance. They are stainless and heat-resistant steels containing minimum $11 \mathrm{wt} \%$ of $\mathrm{Cr}$ and $8 \mathrm{wt} \%$ of $\mathrm{Ni}$. Their global consumption and production is still at a high level, with a rising tendency of $6 \%$ per year on average $[1,2]$. This increases results from the ever new applications of these steels as the undisputed main construction material in many areas of industrial production (Fig. 1). The steels are characterised by a particularly advantageous combination of chemical properties, such as corrosion and oxidation resistance, as well as profitable mechanical properties, such as high plasticity [3-5].

Due to plastic deformation or pressure, in some AISI 300 series steels, austenite (fcc, non-magnetic) can transform into martensite (bcc or hcp, ferromagnetic or paramagnetic) despite the $\mathrm{Ni}$ content which stabilises the austenitic steel structure [6, 7]. A classic example of metastable steel is the widely used steel 304 $(8-10.5 \mathrm{wt} \% \mathrm{Ni})[8,9]$. At higher $\mathrm{Ni}$ concentrations, e.g., in the $316(10-14 \mathrm{wt} . \% \mathrm{Ni})$ and the $310(19-22 \mathrm{wt} \% \mathrm{Ni})$ steels subjected to conventional industrial production processes, austenite is more or completely stable $[10,11]$. However, in the studies of steels subjected to highly imbalanced processes, such as PVD, where the manufacturing conditions correspond to a cooling rate of approximately $10^{15} \mathrm{~K} / \mathrm{s}$, it was shown that even this level of $\mathrm{Ni}$

\footnotetext{
* corresponding author; e-mail: kucharska.barbara@wip.pcz.pl
}

concentration does not stabilise the austenite structure. It was found that coatings made of these steels produced by magnetron sputtering can have a structure of both biphasic fcc/bcc and bcc only $[12,13]$. The possibility of controlled production of magnetic phases in alloys based on austenitic steels promotes their new applications, e.g., in a control apparatus in which, apart from the properties typical of these steels, their magnetic properties are important too $[14,15]$.

In this work, the authors investigate the phase composition of three austenitic steels from the AISI 300 series subjected to fast cooling from the liquid state by being cast on a copper drum (melt spinning). By centrifuging the drum and cooling it from the inside (with water or liquid nitrogen), a thin stream of liquid alloy solidifies at a speed of $10^{4}-10^{7} \mathrm{~K} / \mathrm{s}$. The method successfully used for the production of amorphous metal and amorphous ribbons was experimentally applied to austenitic steels.

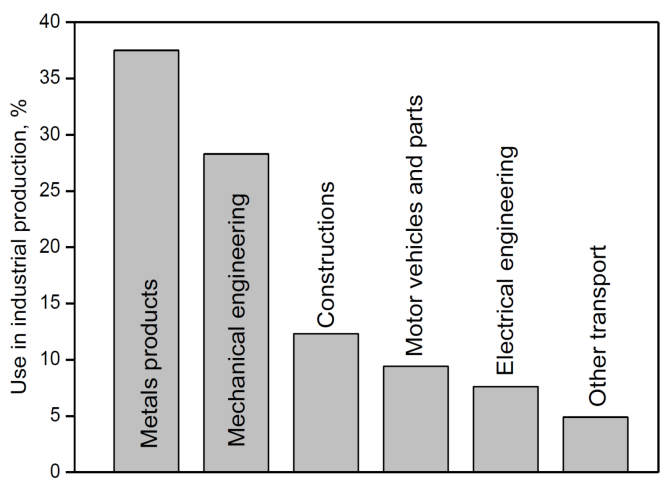

Fig. 1. The use of austenitic corrosion-resistant steels in various fields of industrial production, acc. [15]. 


\section{Material and the test method}

The test material was austenitic chromium-nickel steel of three grades, AISI 304L, 316L, and 310S, in the form of $1 \mathrm{~mm}$ thick sheet metal. The concentrations of alloying additives in the steels are shown in Table I. The steels differs in terms of the concentrations of $\mathrm{Cr}$ and Ni. Moreover, in the 316L steel (the so-called surgical steel) Mo is additionally present, thanks to which the steel exhibits high pitting corrosion resistance at ambient temperature. The 304L and 310S steels are heat-resistant.

Steel sheets from which samples were taken for remelting had the single-phase microstructure of recrystallised austenite (Fig. 2). They were mechanically shredded, and subsequently divided into portions of $13 \mathrm{~g}$. The prepared masses of steel were subjected to the procedure used in the production of amorphous ribbons. First, they were placed in the arc-melter chamber and remelted 5 times with an electric arc. The remelting was preceded by three passages of argon flow through the chamber of the device in order to obtain an oxygen-free atmosphere. Then, a melt spinning method was used to produce ribbons

TABLE I

Normative chemical composition of steels according to EN-10088-2 [wt\%].

\begin{tabular}{c|c|c|c}
\hline \hline Element & $316 \mathrm{~L}$ & $304 \mathrm{~L}$ & $310 \mathrm{~S}$ \\
\hline $\mathrm{C}$ & $\max .0 .03$ & $\max .0 .03$ & $\max 0.08$ \\
$\mathrm{Cr}$ & $16-18$ & $17.5-19.5$ & $24-26$ \\
$\mathrm{Ni}$ & $10-14$ & $8-12$ & $19-22$ \\
$\mathrm{Si}$ & 1.0 & 1.0 & 1.5 \\
$\mathrm{Mo}$ & $2-3$ & - & - \\
$\mathrm{Mn}$ & \multicolumn{3}{|c}{$\max .2 .0$} \\
$\mathrm{P}$ & & max. 0.045 \\
$\mathrm{~S}$ & & max. 0.03 \\
$\mathrm{Fe}$ & & balance
\end{tabular}

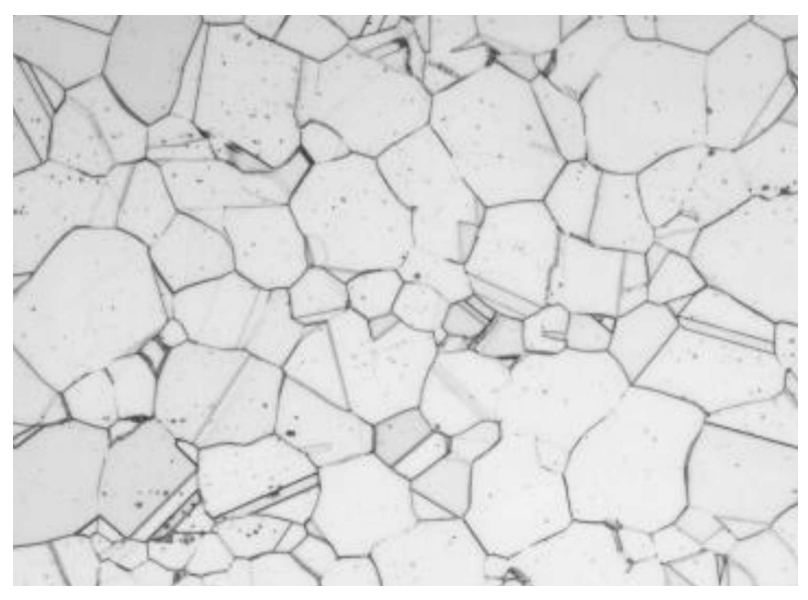

Fig. 2. Microstructure of 316L steel in a condition prior to arc-melting.
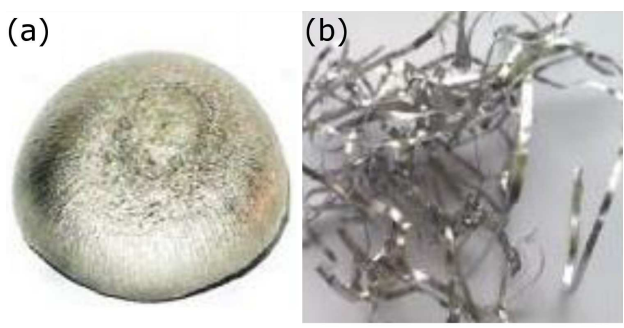

(c)
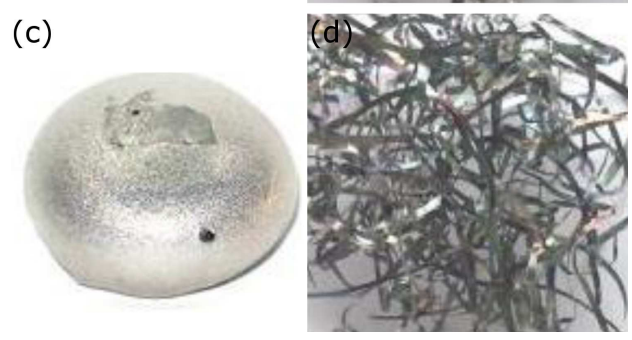

Fig. 3. General view of steel after remelting in the arc and after making tapes by casting on the drum (a), (b) 304L and (c), (d) 310S.

of melted steel in a different device. A spinning drum $(4000 \mathrm{rpm}=31 \mathrm{~m} / \mathrm{s})$ in the chamber of the device with the underpressure of $0.03 \mathrm{MPa}$ was cooled from the inside with water. The inductively melted alloys solidified on the spinning drum in the shape of thin ribbons.

A general view of the manufactured alloys at each stage of the experiment is shown in Fig. 3.

\section{Methodology}

The prepared alloys were examined for microstructure by means of light microscopy and scanning microscopy (Joel JSM 5400) as well as by X-ray diffractomery (Seifert 3003TT) using filtered radiation $\mathrm{K}_{\alpha} \mathrm{Co}=0.17902 \mathrm{~nm}$, generated with voltage and current of $U=30 \mathrm{kV}$ and $I=40 \mathrm{~mA}$, respectively. Microscopic and diffractometric tests were performed on cross-sections of the arcmelted steel and on the surface of ribbons. Diffraction studies were carried out in the range of diffraction angles of $20-120^{\circ}$ with a scanning step of $0.15^{\circ}$ and during the counting of $5 \mathrm{~s}$.

\section{Results}

The microstructure of the arc-remelted steel is shown in Fig. 4. After remelting, microstructures, typical of the solidification process, revealed the directional growth of crystallites (dendrites). Dendrites were the most developed in the $316 \mathrm{~L}$ steel. In the interdendritic spaces, phases that were the effects of segregation of ingredients occurred. In the 304L steel microstructure, the formation of dendrites proved to be smaller, and the segregation of constituents was minimal, as in the $310 \mathrm{~S}$ steel, where mainly the microstructure of columnar crystallites was formed. Due to a higher content of carbon in the $310 \mathrm{~S}$ steel (0.08 wt.\%), chromium carbides separated on the boundaries of columnar crystallites. 
(a)

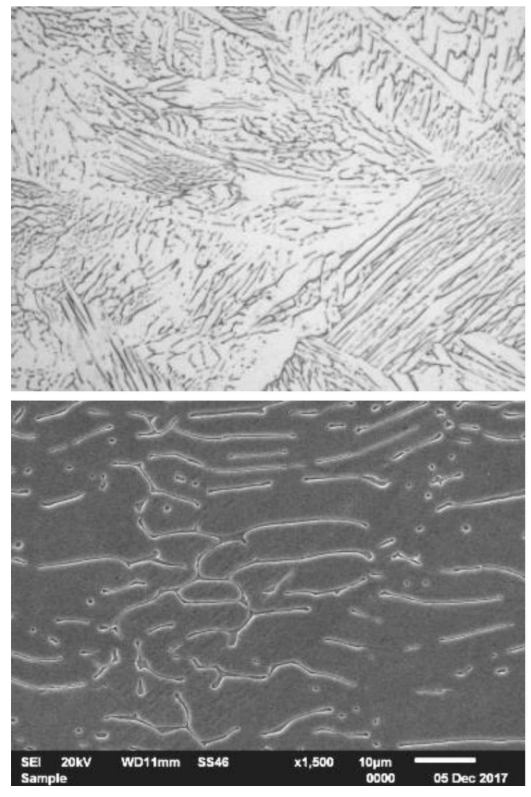

(b)
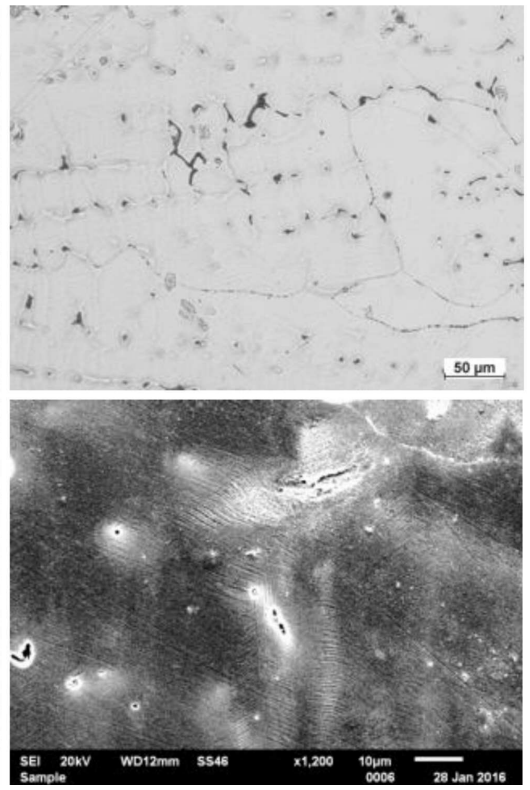

(c)

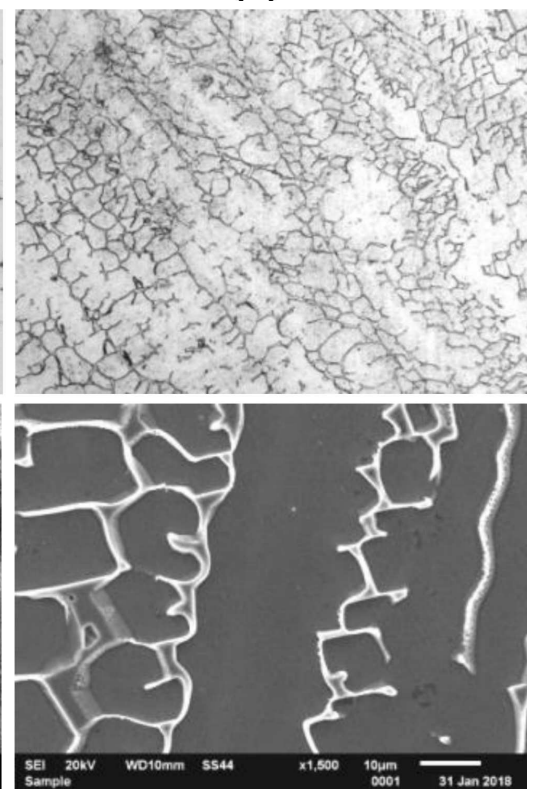

Fig. 4. Microstructure of steel (a) 304L, (b) 310S and (c) 316L after arc-melting (light microscope and SEM).

The chemical composition of the melted steel was determined using X-ray microanalysis. The EDX analysis was performed on steel cross-sections in the area of $0.35-1.3 \mathrm{~mm}^{2}$. Table II presents the results of the analysis. For the $304 \mathrm{~L}$ steel, the chemical composition was also determined on the ribbon in an area of approximately $3 \mathrm{~mm}^{2}$.

It was found that the concentrations of elements in the chemical composition remained in the proportions corresponding to the steels used for remelting. It can be seen that the concentrations of $\mathrm{Cr}$ in the melted steels are close to the maximum value provided for them by the EN-10088-2 standard, while the concentration of nickel is close to the minimum value. The control analysis on a $304 \mathrm{~L}$ steel ribbon also confirmed a normative concentration of ingredients (Table II, Fig. 5).

Figure 6 presents a list of steel diffractograms at each of the production stages, i.e., in the initial state (steel sheets), after arc-melting and after melt-spinning. The diffractograms of all steels in the initial state reveal the structure of austenite $\gamma$. The mutual intensities of diffraction reflections, diverging slightly from the phase pattern, reflected the texture usually exhibited by rolled steel sheets, and which were used as a starting material for testing. After remelting in the arc, they still had austenite structure, except that small quantities of ferrite $\delta$ (bcc) were created in the 316L and 304L steels (Fig. 6a, c). The precise determination of the volume fraction of this phase on the basis of the diffractogram was not possible due to the emerging solidification texture, especially in case of the 304L steel (anomalously strong reflex 200). However, it can be estimated that the bcc phase share did not exceed 10 vol.\%.
TABLE II

Chemical composition of steel (EDX) after arc-melting and casting on a drum [wt\%].

\begin{tabular}{c|c|c|c|c}
\hline \hline Element & $\begin{array}{c}304 \mathrm{~L} \\
\text { arc-melted }\end{array}$ & $\begin{array}{c}304 \mathrm{~L} \\
\text { melt-spinned }\end{array}$ & $\begin{array}{c}310 \mathrm{~S} \\
\text { arc-melted }\end{array}$ & $\begin{array}{c}316 \mathrm{~L} \\
\text { arc-melted }\end{array}$ \\
\hline $\mathrm{Si}$ & 0.4 & 0.6 & 0.6 & 0.4 \\
$\mathrm{Cr}$ & 18.2 & 18.9 & 25.9 & 18.5 \\
$\mathrm{Mn}$ & 1.7 & 1.4 & 1.4 & 1.9 \\
$\mathrm{Fe}$ & 70.8 & 70.9 & 52.2 & 67.3 \\
$\mathrm{Ni}$ & 8.9 & 8.1 & 19.8 & 9.4 \\
$\mathrm{Mo}$ & - & - & - & 2.5
\end{tabular}

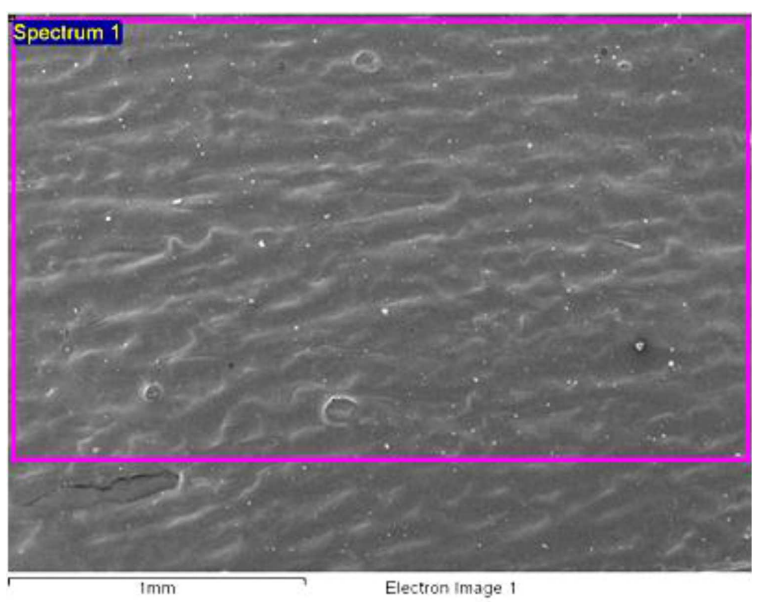

Fig. 5. The surface of a 304L steel strip cast on a drum with an indication of the EDX analysis area. 

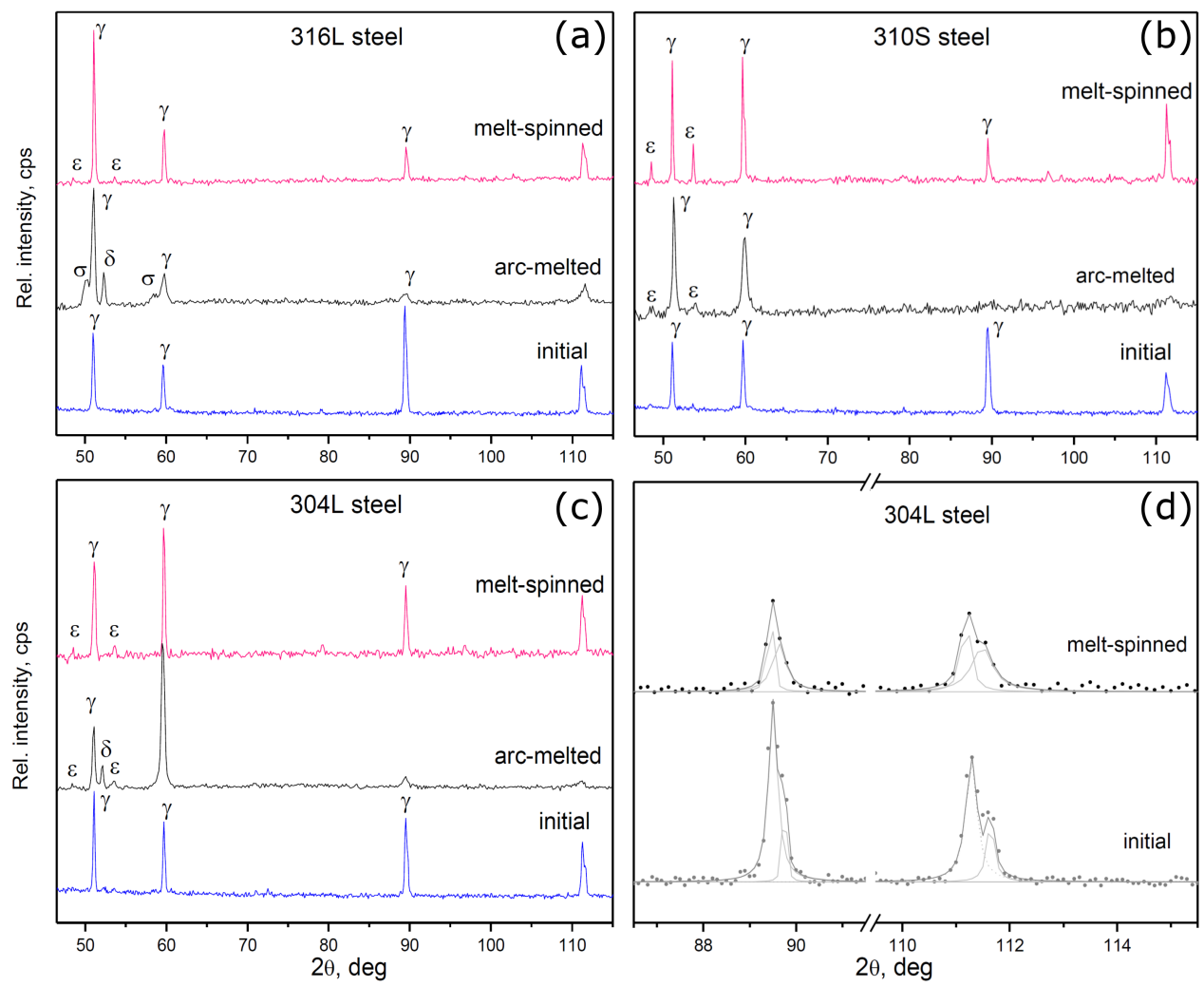

Fig. 6. Diffractograms of steel (a) 304L, (b) 316L and (c), (d) 310S in the initial state, arc-melted and melt-spinned.

On the diffractogram of the melted 316L steel, reflections associated with $\sigma$ phase (tcp) were also noted, which suggests its presence in the interdendritic areas (see Fig. 4c). In the melted steels $310 \mathrm{~S}$ and $304 \mathrm{~L}$, there were also very weak reflections associated with martensite $\varepsilon$ (hcp) (Fig. 6a, b).

All the steels produced in the form of a ribbon had an fcc structure with different degrees of texturing, the largest in the 304L steel, and the smallest in the 316L steel. Additionally, in all ribbons martensite $\varepsilon$ was formed (Fig. 6b). Definitely the biggest amount was found in the $310 \mathrm{~S}$ steel ribbon $(<10$ vol. $\%$ ). In other ribbons, martensite $\varepsilon$ was represented on diffractograms with very weak reflections (only about 3 vol.\%) emerging from the background. The half widths of the diffraction reflections from the austenite in the ribbons were larger compared to the reflections from the steel in the initial state (Fig. 6d). Therefore, as expected, as a result of melt-spinning, the separation of the austenite crystallites was obtained.

\section{Conclusions}

The studies showed the influence of the cooling rate and the mutual relationship of concentrations of $\mathrm{Cr}$ and $\mathrm{Ni}$ alloy additives in austenitic corrosion resistant steels on the type of martensitic phase formed in them. Using the XRD method, it was shown that alloys of austenitic steels in the AISI300 series (304L, 316L, and 310S) subjected to free cooling after remelting in the arc and quick cooling from the liquid phase on a copper drum rotating at about $4000 \mathrm{rpm}$ assume the austenite structure. However, as a result of solidification, non-equilibrium martensite is additionally formed in the alloys. The result of melt spinning is martensite $\varepsilon$. The most martensite $\varepsilon$ is formed in the $310 \mathrm{~S}$ steel. The $310 \mathrm{~S}$ steel contains more carbon (maximum 0.08 wt.\% C) and chromium compared to the $304 \mathrm{~L}$ and $316 \mathrm{~L}$ steels (maximum 0.03 wt.\% C). Carbon and chromium favour the formation of martensite, which explains the larger proportion of this phase in the structure of the $310 \mathrm{~S}$ melt-spinned steel, but also the one remelted in the arc, where the cooling takes place at a lower rate. No ferrite $\delta$ is formed on any $310 \mathrm{~S}$ grade steel. Ferrite $\delta$ is formed in both alloys with lower concentrations of $\mathrm{C}$ and $\mathrm{Cr}(304 \mathrm{~L}$ and $316 \mathrm{~L})$, only in terms of free solidification after arc-melting. The formation of ferrite $\delta$ in alloys with a lower concentration of ferriteforming additives suggests that the ratio of mutual $\mathrm{Cr} / \mathrm{Ni}$ concentrations is also important. In the alloys made of the $304 \mathrm{~L}$ and $316 \mathrm{~L}$ steel, it was 1.9 and 2.2 , respectively, and in the 310S steel alloy, only 1.3 .

As a result of the cooling rate typical of the casting method on a copper drum, only martensite $\varepsilon$ is formed in the AISI300 series steels. The lower the $\mathrm{Cr} / \mathrm{Ni}$ concentrations are, the higher the volume fraction of martensite $\varepsilon$ is. 


\section{References}

[1] Handbook of Stainless Steel, Ed. Outokumpu Oyj, 2013.

[2] H. Bhadeshia, R. Honeycombe, Stainless Steel in: Steels: Mictrostructure and Properties (4th ed.), Chapter 12, Butterworth-Heinemann, Oxford 2017, p. 343.

[3] K.H. Lo, C.H. Shek, J.K.L. Lai, Mater. Sci. Eng. R65, 39 (2009).

[4] X. Li, X. Wei, J. Lu, J. Ding, W. Wang, Energy Procedia 142, 3590 (2017).

[5] J.E. Tang, M. Halvarsson, H. Asteman, J.E. Svensson, Micron 32, 799 (2001)

[6] A. Das, P.C. Chakraborti, S. Tarafder, H. Bhadeshia, Mater. Sci. Tech. 27, 1, 366 (2011).

[7] J. Hawreliak, J.D. Colvin, D.H. Kalantar, H.E. Lorenzana, J.S. Stolken, H.M. Davies, T.C. Germann, B.L. Holian, K. Kadau, P.S. Lomdahl, A. Higginbotham, K. Rosolankova, J. Sheppard, J.S. Wark, Phys. Rev. B 19, 41 (2006).

[8] M. Milad, N. Zreiba, F. Elhalouani, C. Baradi, J.Mat.Proc.Tech. 203, 80 (2008).

[9] E. Dryzek, M. Sarne, Acta Phys. Pol. A 125, 3, 710 (2014).
[10] B. Kucharska, M. Krzywiecki, T. Nowak, Inż.Mater.Mater.Eng. 6, 409 (2015) (in Polish).

[11] K. Datta, R. Delhez, P.M. Bronsveld, J. Beyer, H.J.M. Geijselaers, J. Post, Acta Mater. 57, 3321 (2009).

[12] X. Zhang, A. Misra, R.K. Schulze, C.J. Wetteland, H. Wang, M. Nastasi, J.Mater.Res. 19, 6, 1696 (2004).

[13] B. Kucharska, "PVD coatings made of chromiumnickel steel modified with additives $\mathrm{Al}, \mathrm{Ir}, \mathrm{Re}$ and Ru", Series: Monographs No. 21, Faculty of Production Engineering at Czestochowa Univ. of Technology, Częstochowa 2011 (in Polish).

[14] J. Kaleta, "SMART magnetic materials. Construction, manufacture, testing properties, application", Wroclaw Univ. of Technology Publishing House, Wrocław 2013 (in Polish).

[15] J. Kaleta, P. Wiewiórski, W. Wiśniewski, Investigation of Martensitic Transformation Induced by Cyclic Plastic Deformation in Austenitic Steels in: Austenitic Stainless Steels - New Aspects, Eds. W. Borek, T. Tanski, Z. Brytan, IntechOpen, Rijeka 2017. 